\title{
Dynamic Time-History analyses of Ground Reinforced Concrete Tank in Water Supply System under Bi-directional Horizontal Seismic Actions
}

\author{
Wang Mingzhen ${ }^{a}$, Gao Lin ${ }^{b}$ \\ Chongqing University of Arts and Sciences, 319 Hong He Street, Yong Chuan District, Chongqing \\ 402160, China \\ awmz917@126.com, bgaolin32@163.com
}

\begin{abstract}
Keywords: fluid-filled structure; ADINA; bi-directional horizontal seismic actions; dynamic characteristic; the maximum sloshing wave height; hydrodynamic pressure

Abstract. The reinforced concrete tank in water supply system is a typical fluid-filled structure. There are liquid-solid couple effects and liquid sloshing in the fluid-filled structure under seismic actions. The existence of liquid storage changes the dynamic characteristics and seismic responses of the structure. The research objects are the ground circular tanks commonly used in water supply system. The finite element software ADINA is used to analyze the dynamic characteristics of the tanks firstly. Seven pairs of natural seismic records in the Wenchuan main shock are selected as bi-directional horizontal seismic inputs. The effects of water storage height, tank radius and ground motion characteristics on the maximum sloshing wave height of liquid surface and hydrodynamic pressure are analyzed according to the finite element analyses results. The distribution rules of the maximum sloshing wave height of liquid surface and hydrodynamic pressure are also given. The research results of this paper can provide references for tank seismic design.
\end{abstract}

\section{Introduction}

Water tank is an important structure in water supply system, which takes the important role of water storage and purification. Tank can be divided into circular tank and rectangular tank by plane shape. The tanks are prone to damage, including the occurrence of cracks in tank body, the loss of internal liquid storage and the tank structure function under strong earthquakes such as Tangshan earthquake, Wenchuan earthquake and Yushu earthquake. The circular tank of water supply system is taken as the research object in this paper since the circular tank more widely used in practical engineering has more advantages than rectangular tank in terms of construction and structure stress. The fluid-filled structure is different from the general building structure due to the existence of internal liquid. The internal liquid will shake under seismic actions, which will change the liquid pressures on tank body, liquid sloshing also consume seismic input energy.

At present, the dynamic time-history response of fluid-filled structure under seismic actions has been analyzed by some domestic and foreign researchers ${ }^{[1-8]}$. But most of the analyses are about the seismic responses under unidirectional horizontal seismic action and rarely under bi-directional horizontal seismic actions. The actual earthquake occurs are often accompanied by the two-way horizontal and vertical way earthquake interactions. Vertical seismic action have a great impact on large span structures, high-rise structures and so on, but have little effect on the structures of smaller size and height. The authors also analyzed the circular tank seismic responses under vertical seismic action. The fact indicates that the response of liquid-solid coupling system is exactly the same as that under only horizontal seismic action considering both the unidirectional horizontal seismic action and the vertical seismic action or the bidirectional horizontal seismic action and the vertical seismic action together. So the seismic response of tank cannot consider the vertical seismic action influence. However, the responses of the tank liquid-solid coupling system under unidirectional horizontal seismic or bi-directional horizontal seismic action are different. Compared with the unidirectional horizontal seismic action, the seismic response of tank under bi-directional horizontal earthquake is more consistent with the actual situation, which can more reasonably simulate the tank seismic response. Therefore, the dynamic characteristics of circular tank liquid-solid coupling system are 
analyzed firstly, and then seven pairs of natural seismic records in the Wenchuan main shock are selected. The dynamic time-history responses are analyzed, and the distribution law of the maximum wave height and hydrodynamic pressure are studied.

\section{The finite element models of circular tank considering liquid-solid coupling}

The analyzed tank types are defined as a ground, no head cover circular tank with capacities of $500 \mathrm{~m}^{3}$, $200 \mathrm{~m}^{3}$ and $2000 \mathrm{~m}^{3}$, respectively according to the Specification for structural design of reinforced concrete water tank of water supply and sewerage engineering (CECS 138: 2002), the Circular reinforced concrete reservoir atlas $(04 \mathrm{~S} 803)$ and structure commonly used in practical engineering. In order to express analytical results later, the three tanks referred to tank A, B and C in the order of capacity. The specific parameters of three tanks are shown in Table 1, and the corresponding relation between the water storage capacity and water storage height are shown in Table 2.

Table 1 The specific parameters of three circular tanks

\begin{tabular}{cccccccccc}
\hline name & $\begin{array}{c}\text { capacity } \\
{\left[\mathrm{m}^{3}\right]}\end{array}$ & $\begin{array}{c}\text { Thickness } \\
\text { of tank } \\
\text { bottom } \\
{[\mathrm{m}]}\end{array}$ & $\begin{array}{c}\text { Thickness } \\
\text { of tank } \\
\text { wall } \\
{[\mathrm{m}]}\end{array}$ & $\begin{array}{c}\text { inner } \\
\text { radius } \\
{[\mathrm{m}]}\end{array}$ & $\begin{array}{c}\text { inner } \\
\text { diameter } \\
{[\mathrm{m}]}\end{array}$ & $\begin{array}{c}\text { Total } \\
\text { height } \\
{[\mathrm{m}]}\end{array}$ & $\begin{array}{c}\text { The } \\
\text { maximum } \\
\text { water storage } \\
\text { height }[\mathrm{m}]\end{array}$ & $\begin{array}{c}\text { rebar } \\
\text { diamete } \\
\mathrm{r} \\
{[\mathrm{mm}]}\end{array}$ & $\begin{array}{c}\text { section } \\
\text { area of the } \\
\text { rebar } \\
{\left[\mathrm{mm}^{2}\right]}\end{array}$ \\
\hline A & 500 & 0.3 & 0.25 & 6.75 & 13.5 & 3.8 & 3.5 & 10 & 79 \\
B & 200 & 0.3 & 0.25 & 4.3 & 8.6 & 3.8 & 3.5 & 10 & 79 \\
C & 2000 & 0.3 & 0.25 & 13.5 & 27.0 & 3.8 & 3.5 & 10 & 79 \\
\hline
\end{tabular}

Table 2 The corresponding relation between the water storage capacity and water storage height

\begin{tabular}{ccccccccc}
\hline water storage capacity & No water & $10 \%$ & $20 \%$ & $30 \%$ & $40 \%$ & $50 \%$ & $60 \%$ & $70 \%$ \\
\hline water storage height $(\mathrm{m})$ & 0 & 0.35 & 0.70 & 1.05 & 1.40 & 1.75 & 2.10 & 2.45 \\
\hline
\end{tabular}

The condition of $500 \mathrm{~m}^{3}$ capacity and $2.45 \mathrm{~m}$ water storage tank height is indicated by "A-70\%". Because of the tank normal water storage capacity is seventy percent of the total capacity. Therefore, the maximum water storage capacity is seventy percent. The material properties of water are listed in Table 3.

Table 3 The material properties of water

\begin{tabular}{ccc}
\hline density $\left(\mathrm{Kg} / \mathrm{m}^{3}\right)$ & bulk modulus $(\mathrm{Pa})$ & damping ratio \\
\hline 1000 & $2.3 \times 10^{9}$ & $0.16 \%$ \\
\hline
\end{tabular}

\section{Seismic inputs}

In order to study the effects of site classification and epicentral distance on the tank liquid-solid coupling system and correctly simulate the seismic responses of the structure system, seven pairs of natural seismic records with amplitude about 100gal in the Wenchuan main shock are selected. The time interval of seismic records is $0.005 \mathrm{~s}$. The duration of seismic records is $30 \mathrm{~s}$. The basic information of the selected seismic records are shown in Table 4. 
Table 4 The basic information of selected seismic records

\begin{tabular}{|c|c|c|c|c|c|}
\hline $\begin{array}{c}\text { Station name } \\
\text { (province) }\end{array}$ & $\begin{array}{c}\text { Site } \\
\text { classification }\end{array}$ & $\begin{array}{c}\text { Epicentral } \\
\text { distance }[\mathrm{km}]\end{array}$ & Direction & $\begin{array}{c}\text { Acceleration } \\
\text { peak [gal] }\end{array}$ & $\begin{array}{c}\text { Predominant } \\
\text { period }[\mathrm{s}]\end{array}$ \\
\hline \multirow{2}{*}{$\begin{array}{c}\text { HSDB } \\
\text { (Sichuan) }\end{array}$} & \multirow{2}{*}{ II } & \multirow{2}{*}{125.9} & EW & -102.643 & 0.095 \\
\hline & & & NS & 89.129 & 0.111 \\
\hline \multirow{2}{*}{$\begin{array}{c}\text { JZGYF } \\
\text { (Sichuan) }\end{array}$} & \multirow{2}{*}{ II } & \multirow{2}{*}{263.3} & EW & -91.813 & 0.151 \\
\hline & & & NS & 100.224 & 0.168 \\
\hline \multirow{2}{*}{$\begin{array}{c}\text { PJW } \\
\text { (Sichuan) }\end{array}$} & \multirow{2}{*}{ II } & \multirow{2}{*}{81.0} & $\mathrm{EW}$ & 97.454 & 0.310 \\
\hline & & & NS & 101.149 & 0.297 \\
\hline \multirow{2}{*}{$\begin{array}{c}\text { BJ } \\
\text { (Shanxi) }\end{array}$} & \multirow{2}{*}{ III } & \multirow{2}{*}{513.1} & EW & 120.292 & 0.611 \\
\hline & & & NS & -90.121 & 0.532 \\
\hline \multirow{2}{*}{$\begin{array}{c}\text { CC } \\
\text { (Shanxi) }\end{array}$} & \multirow{2}{*}{ III } & \multirow{2}{*}{528.6} & EW & 91.260 & 0.719 \\
\hline & & & NS & 107.719 & 1.138 \\
\hline \multirow{2}{*}{$\begin{array}{c}\text { YL } \\
\text { (Shanxi) }\end{array}$} & \multirow{2}{*}{ III } & \multirow{2}{*}{569.9} & EW & 77.602 & 1.950 \\
\hline & & & NS & -94.005 & 1.862 \\
\hline \multirow{2}{*}{$\begin{array}{c}\text { HX } \\
\text { (Shanxi) }\end{array}$} & \multirow{2}{*}{ III } & \multirow{2}{*}{599.0} & $\mathrm{EW}$ & 67.806 & 1.138 \\
\hline & & & NS & 92.090 & 4.096 \\
\hline
\end{tabular}

\section{Dynamic characteristics of liquid-solid coupling system}

Only the structural vibration mode of the whole structure exists when there is no water in the tank. But there are three kinds of mode include rigid modal, low order liquid sloshing mode and high order structure vibration mode when there is water in the tank. The presence of liquid in the tank significantly changes the dynamic characteristics of the whole system. In order to study the influence of water storage height on the system dynamic characteristics, the first 23 modal frequencies at different water storage heights of tank A are plotted in Fig.1. It can be seen from Fig. 1 that the first order frequencies are all rigid modes at different water storage heights. The liquid sloshing frequency at the same order increases with the increase of water storage height. The liquid sloshing frequencies change dramatically when water storage height is less than $50 \%$. The liquid sloshing frequencies have small changes when water storage height is more than $50 \%$, and the difference of higher order frequency values are smaller. Due to the symmetry of circular tank, the frequencies appear in pairs. The water storage height has little effect on liquid sloshing frequency.
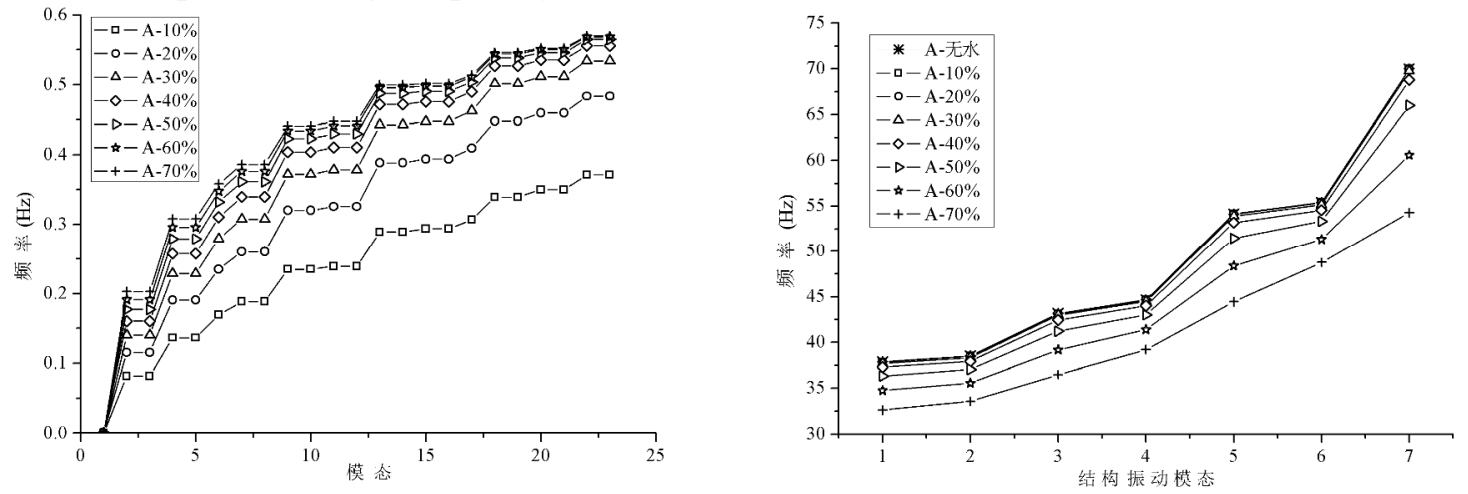

Fig.1 The first 23 liquid sloshing frequencies of tank A Fig.2 The first 7 structure vibration frequencies of tank A

The first 7 order structure vibration frequency curve of the circular tank A is plotted in Fig.2. When the water storage height is not more than $30 \%$, the structure vibration frequency does not differ from the waterless structure. When water storage height is larger, the structure vibration frequency is quite different from the waterless state. The structure vibration frequency of the same-order decreases with the increase of water storage height, which indicates that the more significant the liquid-solid coupling 
effect, the larger water storage height. The influence of liquid on the structure vibration can be seen through the change of structure vibration frequency.

In order to analyze the effect of tank radius on the liquid-solid coupling modalities, the frequency calculations for tank A, B and C with 2.45 meter water storage height are shown in Table 5. It can be seen from Table 5 that the liquid sloshing frequency and structure vibration frequency both decrease with the increase of tank radius. The larger the tank radius, the more significant liquid-solid coupling effects. The tank radius has little effect on the vibration mode of liquid sloshing and has a great influence on the vibration mode of structure vibration ${ }^{[9]}$.

Table 5 The frequency calculations for tank A, B and C with 2.45 meter water storage height (Hz)

\begin{tabular}{cccc}
\hline Mode order & Tank B & Tank A & Tank C \\
& $(4.3 \mathrm{~m}$ radius $)$ & $(6.75 \mathrm{~m}$ radius $)$ & $(13.5 \mathrm{~m}$ radius $)$ \\
\hline The first frequency of liquid sloshing & 0.30 & 0.20 & 0.11 \\
The second frequency of liquid sloshing & 0.57 & 0.44 & 0.27 \\
The third frequency of liquid sloshing & 0.73 & 0.57 & 0.38 \\
The first frequency of structure vibration & 39.22 & 33.07 & 25.16 \\
The second frequency of structure vibration & 42.19 & 34.01 & 25.58 \\
The third frequency of structure vibration & 49.28 & 36.99 & 25.86 \\
\hline
\end{tabular}

\section{The maximum sloshing wave height of liquid surface}

Based on the time-history analyses with different water storage heights and different radii under bi-directional horizontal seismic actions at peak accelerations 100gal, 200gal and 400gal, the duration and the maximum of sloshing wave height for liquid surface are proposed. The maximum sloshing wave height values of liquid surface for part calculation conditions under peak accelerations of 100gal are listed in Table 6 . The cloud pictures of the maximum vertical displacement namely the maximum wave height are shown in Fig.3.

Table 6 The maximum sloshing wave height values of liquid surface for part calculation conditions under peak accelerations of $100 \mathrm{gal}[\mathrm{m}]$

\begin{tabular}{cccccccc}
\hline $\begin{array}{c}\text { Condition } \\
\text { case }\end{array}$ & HSDB & JZGYF & PJW & BJ & CC & YL & HX \\
\hline A-10\% & 0.0929 & 0.1346 & 0.3194 & 0.1550 & 0.2634 & 0.3686 & 0.3578 \\
A-30\% & 0.1284 & 0.1650 & 0.3659 & 0.2106 & 0.4841 & 1.5138 & 0.7607 \\
A-50\% & 0.1404 & 0.2299 & 0.7099 & 0.4015 & 0.7459 & 1.0299 & 1.3665 \\
A-70\% & 0.1517 & 0.3475 & 0.8958 & 0.5309 & 1.1778 & 1.2962 & 1.1479 \\
B-70\% & 0.1779 & 0.1553 & 0.4910 & 0.2574 & 0.6288 & 1.1660 & 1.2383 \\
C-70\% & 0.1692 & 0.3305 & 0.7480 & 0.2492 & 0.4697 & 1.1937 & 0.8384 \\
\hline
\end{tabular}

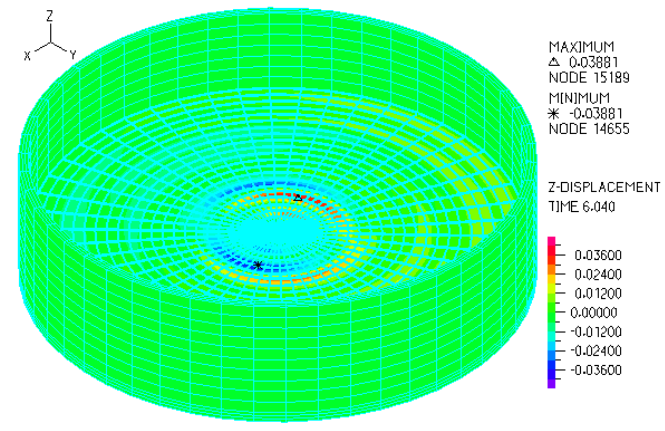

a) HSDB bi-directional seismic action

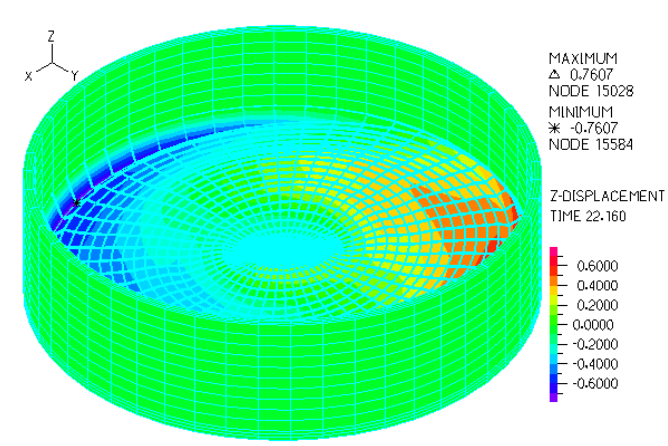

b) HX bi-directional seismic action

Fig.3 The cloud pictures of the maximum vertical displacement for A-30\% condition under bi-directional horizontal seismic actions at peak accelerations $100 \mathrm{gal}$

It can be seen that the sloshing wave height of liquid surface increases proportionally with the increase of acceleration peak under the same seismic action and different peak acceleration when the 
tanks do not occur serious damage according to the calculation results of each conditions. The maximum sloshing wave height of liquid surface usually appears in the position of circle radius under the long period bi-directional horizontal seismic actions, and the maximum sloshing wave appears at the same time and position when the peak acceleration differ. The sloshing amplitude under long period seismic actions is greater than under short period seismic actions ${ }^{[10]}$.

\section{Hydrodynamic pressure}

In addition to the hydrostatic pressure at the tank bottom and wall, the hydrodynamic pressure also exists due to the liquid sloshing under seismic actions. It is found that the hydrodynamic pressure distribution of the tank bottom plate under bi-directional horizontal seismic actions is that the largest hydrodynamic pressure locates at the circle radius position and the smallest locates at the central point position of tank bottom plate based on the analyses results. Therefore, the hydrodynamic pressure distribution on tank wall at the location of the maximum circle radius can represent the maximum hydrodynamic pressure of the whole tank under bi-directional horizontal seismic actions. Taking the bi-directional seismic action of HSDB and HX as examples, the hydrodynamic pressure distribution of tank wall is plotted in Fig.4.

As can be seen from Fig.4, for short period seismic actions, the maximum hydrodynamic pressure along the wall height orientation is at the bottom and the minimum is at the liquid surface. For long period seismic actions, the hydrodynamic pressure from the liquid surface to the bottom along the wall height orientation change little. Due to the different storage heights, the position of the maximum hydrodynamic pressure is at liquid surface or the bottom ${ }^{[10]}$. The water storage height has a great influence on the hydrodynamic pressure distribution of tank wall.

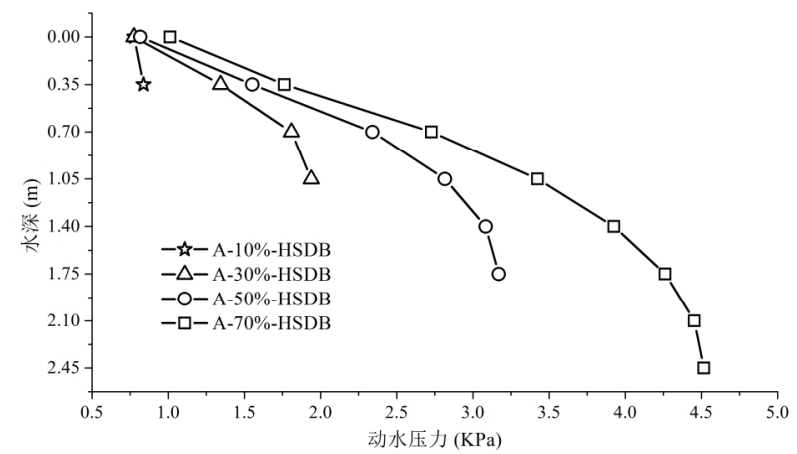

a) HSDB bi-directional seismic action

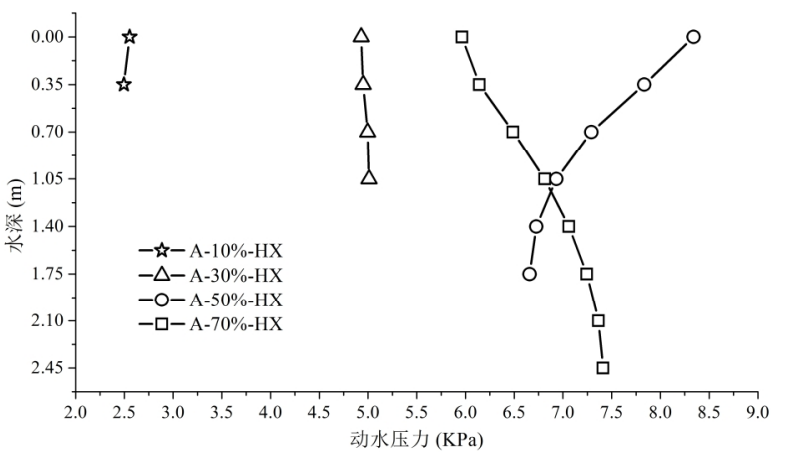

b) HX bi-directional seismic action

Fig.4 The maximum hydrodynamic pressure along the wall height orientation with different water storage height under bi-directional horizontal seismic actions at peak accelerations 100gal

The hydrodynamic pressure distributions of tank wall for different tank radius under the HSDB and HX bi-directional horizontal seismic actions at peak acceleration 100gal are shown in Fig.5. It can be seen from Fig. 5 that, the tank radius has little influence on hydrodynamic pressure distribution of tank wall under short period seismic actions, and showing the distribution of the liquid surface smallest and the bottom largest. Under long period seismic actions, the hydrodynamic pressure from liquid surface to the bottom along the wall height orientation change little, close to the rectangular distribution. The position of the maximum hydrodynamic pressure for tank wall changes from the bottom to liquid surface when the tank radius changes from large to small. The effect of tank radius on wall hydrodynamic pressure distribution is smaller than that of water storage height. 


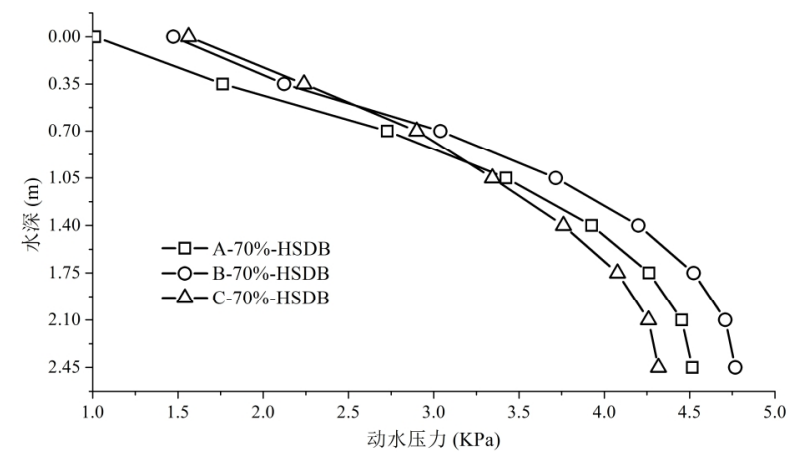

a) HSDB bi-directional seismic action

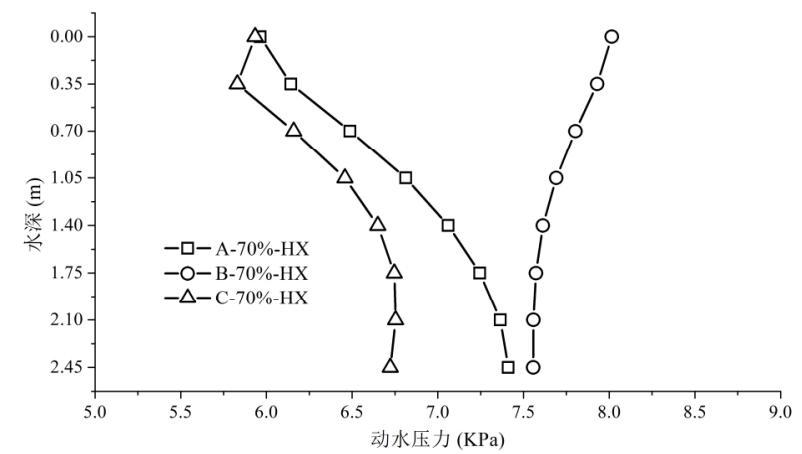

b) HX bi-directional seismic action

Fig.5 The maximum hydrodynamic pressure along the wall height orientation with different tank radius under bi-directional horizontal seismic actions at peak accelerations 100gal

\section{Conclusions}

Through the dynamic response analyses of the circular tank under bi-directional horizontal seismic actions, the dynamic characteristics of the reinforced concrete storage tank are obtained, including liquid sloshing mode and structure vibration mode. The maximum sloshing wave height under different condition cases is studied, including the effect of water storage height and tank radius on the maximum sloshing wave height. The distribution regularities of hydrodynamic pressure on tank wall under bi-directional horizontal seismic actions are analyzed, including the effects of long or short period seismic actions, water storage height and tank radius on hydrodynamic pressure distribution. The results of this paper can provide references for the seismic design of tanks in water supply system.

\section{Acknowledgements}

This work was financially supported by Scientific and Technological Research Program of Chongqing Municipal Education Commission( KJ1601132 ), scientific research fund for Chongqing University of Arts and Sciences (R2015JJ06, 2017RJJ32) and National Natural Science Foundation of China (51678544).

\section{References}

[1] Housner G W: The dynamic behavior of water tanks. Bulletin of the Seismological Society of America, 1963, 53(2):381-387.

[2] HarounMA: Vibration studies and tests of liquid storage tanks. Earthquake Engineering and Structural Dynamics, 1983, 11(2):179-206.

[3] Chen JZ, Kianoush M R: Seismic response of concrete tanks for liquid containing structures, Canadian Journal of Civil Engineering, 2005, 32:739-752.

[4] Chen Huaming, Li Jie, Fan Minquan, Peng Chunqiang: Dynamic Analysis of the Interaction Between the Prestressed Egg-Shaped Digester and Liquid, Engineering Mechanics, 2006, 23(10):49-54.

[5] Chen Zhitao: ADINA Finite Element Analysis of Fluid-Structure Interaction Effect on Egg-Shaped Digester, Tianjin University, 2007.

[6] Du Yongfeng, Shi Xiaoyu, Cheng Xuansheng: Dynamic Analysis of Reinforced Concrete Rectangular Liquid Storage Structures Considering Liquid-Structure Interaction, 2008, 30(1): 21-26.

[7] Xie Jian, Wang Weina, Li Bo: Dynamic characteristics and nonlinear seismic response analysis of large-scale LNG storage tanks, 2013, 43(s1):1273-1277. 
[8] Hashemi S, Saadatpour M M and Kianoush M R: Dynamic analysis of flexible rectangular fluid containers subjected to horizontal ground motion. Earthquake Engineering and Structural Dynamics, 2013, 42(11): 1637-1656.

[9] Gao Lin, Wang Mingzhen: The modal analyses considering liquid-structure coupling effect of ground reinforced concrete circular tanks, 2017, 43(2):47-49.

[10] Gao Lin: Self-healing, Leakage Experimental Investigations and Seismic Response Analyses of the Ground Reinforced Concrete Tank, Institute of Engineering Mechanics, China Earthquake Administration, 2015. 